yet Sc, Sr and Sl of myocardium at the level of the papillary muscle and the apex in patients with IVNC reduced significantly in comparison with those of controls $(p<0.05)$. (3) Weak correlations were noted between the total number of affected segments and LVEF $(r=-0.48, p<0.05)$, LV end-systolic volume $(\mathrm{r}=0.50, \mathrm{p}<0.05)$, LV end-diastolic volume $(\mathrm{r}=0.50, \mathrm{p}<0.05)$ in patients with IVNC.

Conclusions Regional left ventricular systolic dysfunction exists in patients with IVNC. 2DS appears to be the most accurately, sensitively and objectively to detect early left ventricular dysfunction in patients with IVNC (those with normal EF).

\section{[gw22-e0386] ASSESSMENT OF LEFT VENTRICULAR SYSTOLIC FUNCTION IN PATIENTS WITH LEFT VENTRICULAR NON-COMPACTION CARDIOMOPATHY BY ULTRASOUND 2-DIMENSIONAL STRAIN}

Wang Qiao Department Of Ultrasonography, Union Hospital, Tongji Medical College, Huazhong University Of Science And Technology, Wuhan, China

\subsection{6/heartjnl-2011-300867.365}

Objective To assess the left ventricular systolic function in patients with Isolated ventricular non-compaction by twodimensional strain (2DS).

Methods 2D images of three consecutive cardiac cycles at mitral valve, papillary muscle and the apical short-axis views as well as apical long axis, four and two chamber views of left ventricle, were acquired in 20 healthy subjects and 54 patients with IVNC which were divided into two groups with ejection fraction $(E F)<50 \%(n=34)$ and $E F \geq 50 \%(n=20)$, and then the peak systolic circumferential strain $(\mathrm{Sc})$, radial strain $(\mathrm{Sr})$ and longitudinal strain (SI) in IVNC were calculated from 2-dimensional strain and compared among three groups.

Results (1) Compared with healthy and IVNC subjects $(\mathrm{EF} \geq 50 \%)$, Sc, Sr and Sl of myocardium at the level of the mitral annulus, papillary muscle and the apex all reduced significantly in patients with IVNC $(\mathrm{EF}<50 \%)(\mathrm{p}<0.05)$. (2) There were no differences in clinical and traditional echocardiographic characteristics between IVNC (EF $\geq 50 \%)$ and controls ( $p>0.05)$, 